\title{
Correction to: Training Public Sector Clinicians in Competency-Based Clinical Supervision: Methods, Curriculum, and Lessons Learned
}

\author{
Heidi Hutman ${ }^{1} \cdot$ Karen Enyedy ${ }^{2}$ Michael Ellis ${ }^{3} \cdot$ Rodney Goodyear $^{4,5} \cdot$ Carol Falender $^{6,7} \cdot$ Alvaro Campos $^{8}$. \\ Mudita Bahadur ${ }^{9}$. Iore dickey ${ }^{10} \cdot$ Changming Duan $^{11}$. Lisa Ferdinand ${ }^{12} \cdot$ Sarah Nolan $^{13} \cdot$ Tamara Tribitt $^{5}$. \\ Yuying Tsong ${ }^{14} \cdot$ LaTonya Wood $^{6} \cdot$ Heidi Zetzer $^{15}$
}

Published online: 24 April 2021

(c) Springer Science+Business Media, LLC, part of Springer Nature 2021

\section{Correction to: Journal of Contemporary Psychotherapy https://doi.org/10.1007/s10879-021-09499-3}

The original version of this article unfortunately contained error in affiliation section.

All the affiliations are linked erroneously to all the authors in the article. Now, the correct author group along with their corresponding affiliations are listed here.

The original article has been corrected.

The original article can be found online at https://doi.org/10.1007/ s10879-021-09499-3.

Heidi Hutman

Heidi.hutman@temple.edu

Psychological Studies in Education, Temple University, 1301

Cecil B. Moore Ave, Philadelphia, PA 19122, USA

2 Vanderbilt University, Nashville, TN, USA

3 State University of New York At Albany, Albany, NY, USA

4 University of Southern California, Los Angeles, CA, USA

5 University of Redlands, Redlands, CA, USA

6 Pepperdine University, Malibu, CA, USA

7 University of California, Los Angeles, Los Angeles, USA
Publisher's Note Springer Nature remains neutral with regard to jurisdictional claims in published maps and institutional affiliations.
8 Los Angeles County Department of Mental Health, Los Angeles, USA

9 Independent Practice, Santa Monica, CA, USA

10 North Country HealthCare, Flagstaff, AZ, USA

11 University of Kansas, Lawrence, KS, USA

12 University of South Florida, Tampa, FL, USA

13 University of Wisconsin-Madison, Madison, WI, USA

14 California State University, Fullerton, Fullerton, CA, USA

15 University of California, Santa Barbara, Santa Barbara, CA, USA 